\title{
Novas abordagens no ensino das Ciências Humanas: a premência de diversificar linguagens no labor docente com Geografia e História
}

New approaches to the human science teaching: the urgency in diversifying languages in the teacher labor with geography and history

\author{
Adriano Bittencourt Andrade* \\ Universidade de Brasília \\ Nadja Conceição de Jesus Miranda** \\ Universidade Federal da Bahia \\ Dalila Flora Cardoso Varino*** \\ Colégio Militar de Salvador
}

Resumo $\mathrm{O}$ artigo defende que o aprendizado é pessoal e subjetivo derivando, por conseguinte, de estratégias diferenciadas de acesso ao saber formal. Parte do pressuposto que há, invariavelmente, uma diversidade de formas para apreender um dado objeto, e o ferramental a ser utilizado será, sempre, decorrente da combinação heterogênea entre contexto espaço-temporal, instituição de ensino, formação e motivação do professor e o aluno (contexto socioeconômico e individualidade). Assim, este escrito se defronta com uma questão nodal: Como, no ensino das Ciências Humanas, alcançar/comunicar-se com os alunos para além do texto formal? Busca-se, então, compreender a possibilidade de letramento nas Ciências Humanas através da diversificação de estratégias de comunicação; entender as diferentes linguagens como instrumentos para a aproximação do conteúdo programático do cotidiano do aluno e apresentar desafios metodológicos para a utilização de instrumentos de comunicação.

PALAVRAS-CHAVE: Letramento, Ciências Humanas, Estratégias comunicativas.

Abstract The paper is in favor of the learning process as something personal and subjective and that is comes from different strategies to access of formal knowledge. It comes from the assumption that there is invariably from ways to learn an input object and the tool to be used is derived from the heterogeneous combination among the temporal-spatial context, Teaching Institution, teacher motivation and background and the student (social/economical context and individuality) thus, this article faces a nodal issue: How, in the Human Sciences, reach/ communicate with the students beyond the formal text? Considering this topic, it is searched the possibility of literacy in Human Sciences through the diversification of communication strategies; understand the different languages as tools to bring together the students daily syllabus and present methodological challenges to be used as communication tools.

KEYWORDS: Literacy, Human Sciences, Communication Strategies. 
São várias as formas de se comunicar. Diante do imenso lapso que há entre o pensar e o se fazer entender, apropriar-se de diferentes estratégias de comunicação certamente é um caminho mais abrangente para transformar em códigos legíveis, com menor quantidade de ruídos, incompreensões ou desvio de informações, o que se quer dizer.

Especialmente no trato com os ciclos da Educação Básica (Educação Infantil, Ensino Fundamental e Médio), o habitual uso da norma culta, oral ou escrita, para comunicar determinado conteúdo traz diversos desses hiatos de compreensão, visto que o texto formal apresenta consigo uma série de determinâncias para a sua legibilidade, tais quais: conhecimentos prévios, correção e compreensão de estruturas linguísticas e um determinado grau de subjetividade que permita ao leitor fazer conexões entre o conhecido e o apresentado.

Como exemplo e provocação, toma-se o seguinte texto de Koshiba num livro de história voltado para o aluno do Ensino Médio:

[...] Assim, o quadro geral da administração colonial caracterizou-se, no final do século XVIII, pela crescente racionalização da atividade econômica, cujo objetivo era transferência de riqueza do Brasil para Portugal. Paralelamente a essa racionalização aumentava o grau de opressão colonial. (KOSHIBA, 2002, p. 138).

Mesmo com a ressalva de que esse fragmento faz parte de um contexto maior inserido num conteúdo de um capítulo e coerente com os assuntos trabalhados numa lógica encadeada do livro, parece evidente que a assimilação do texto escrito passa pelo entendimento de diversas outras informações que determinam um alto nível de abstração e na capacidade de conectar conceitos e palavras, de forma que o texto escrito em três ou mais linhas passe a ter coerência e significado para o leitor. Considerando que o público alvo desse material é composto, de uma forma geral, de alunos adolescentes, com idade que varia entre os 14 aos 17 anos, acredita-se que, além de não ser atraente, esta forma de comunicação, na maioria das vezes, ou é parcial ou simplesmente não existe.

Um conteúdo apresentado sem que se estabeleça comunicação e, principalmente, significado com o interlocutor, não será apropriado, será depositado e usado para um objetivo imediato, como uma prova, porém sem se constituir na formação de um novo saber no compósito que forma o cidadão estudante.

Emergem da problemática apresentada uma série de questões atreladas umas às outras que induziram o debate e aprofundamento das pesquisas: Como, no ensino das Ciências Humanas (notadamente na abordagem de Geografia e História) ${ }^{1}$, alcançar/comunicar-se com os alunos para além do texto formal? Quais as outras formas de linguagens disponíveis para o professor? Quais as estratégias didáticas possíveis para inserir determinadas linguagens na extensa grade curricular? Quais os cuidados metodológicos para adoção e diversificação das práticas comunicativas?

Esses problemas iluminaram as metas a serem alcançadas na construção do artigo. Busca-se, então, com a discussão aqui desenvolvida, compreender a possibilida- 
de de letramento nas Ciências Humanas através da diversificação de estratégias de comunicação; entender as diferentes linguagens como instrumentos para a aproximação do conteúdo programático do cotidiano do aluno; apresentar desafios metodológicos para a utilização de instrumentos de comunicação, além dos textos formais.

Com esse fim, estruturou-se o texto que segue com três seções de desenvolvimento, além desta introdução e das considerações finais. Os itens interiores tratam: (1) Da fundamental discussão sobre importantes questões contemporâneas relacionadas às estratégias de comunicação nas Ciências Humanas; (2) Da historicização acerca dessas novas abordagens comunicativas na academia e das suas repercussões na Educação; (3) Da proposição de desafios teóricos e metodológicos ante à prática didática no uso de novas estratégias de comunicação.

Ressalva-se, desde já, que não se pretende definir tratados ou verdades peremptórias, o que por si só seria incompreensível num texto sobre práticas educativas. Desta forma, segue-se com o texto, trazendo à tona elementos para o debate sobre a prática didática e metodológica do professor de Ciências Humanas na busca de sempre tentar comunicar-se com o seu aluno. Mais que isso, procura-se alimentar discussões sobre as imensas possibilidades de tornar agradável e produtivo o exercício cotidiano decorrente dos contatos entre docentes e discentes.

\section{Invólucro às práticas educativas da contemporaneidade}

Em outras palavras: como alcançar os nossos alunos?

Essa simplificação da questão, que movimenta essa seção, necessita de esclarecimento. Há muito que os alunos não são entendidos como receptáculos vazios a serem preenchidos pelos conteúdos do currículo escolar. Freire, por exemplo, se coloca contra a educação bancária, defendendo um ensino crítico e construtivo:

... quanto mais criticamente se exerça a capacidade de aprender tanto mais se constrói e se desenvolve o que venho chamando "curiosidade epistemológica”, sem a qual não alcançamos o conhecimento cabal do objeto.

\section{$[\ldots]$}

É isto que nos leva, de um lado, à crítica e à recusa ao ensino "bancário", de outro, a compreender que, apesar dele, o educando a ele submetido não está fadado a fenecer, em que pese o ensino "bancário", que deforma a necessária criatividade do educando e do educador, o educando a ele sujeitado pode, não por causa do conteúdo cujo "conhecimento" lhe foi transferido, mas por causa do processo mesmo de aprender, dar, como se diz na linguagem popular, a volta por cima e superar o autoritarismo e o erro epistemológico do "bancarismo". (FREIRE, 1996, p. 13)

O corpo discente é formado por atores sociais que interagem com um espaço geográfico diverso e dinâmico. Sem o entendimento dessa dinâmica têmporo-espacial $^{2}$ que a todos, diferencialmente, envolve, especialmente no contexto em que está inserida a escola/educação básica na contemporaneidade, é impossível pensar numa relação de ensino e aprendizagem significativa. 
E que cenário é esse que se montou na atualidade? Seria pouco preciso construir um contexto único que desprezasse as múltiplas realidades em diferentes escalas de abordagem, entretanto, com menor ou maior alcance, é possível pensar em alguns aspectos presentes numa ampla escala regional brasileira, ainda que se considerem as variáveis locais (de municípios ou mesmo instituições) e mundiais. Assim, relaciona-se, abaixo, quatro elementos dominantes/presentes, no cenário da educação brasileira, que merecem ser considerados:

O avanço técnico conquistado pela humanidade teve, nos últimos anos, um crescimento exponencial, notadamente no tocante às redes de informação e comunicação. Conforme alerta Andrade (2010), a Terceira Revolução Industrial, a expansão das práticas neoliberais e a hegemonia do sistema capitalista no contexto mundial, criou um arcabouço de possibilidades de conexões e trocas em escala planetária, determinando o que, em linhas gerais, se conhece por Globalização. Esse fenômeno, que se dá na numa escala global, tem, inevitavelmente, repercussões na escala do lugar. Definem-se, assim, novos hábitos e práticas sociais, seja pela imposição das verticalidades, ${ }^{3}$ seja pelo campo de possibilidades que se abre a cada cidadão/consumidor, esteja ele em Nova York/EUA (metrópole internacional) ou em Amargosa/Bahia/Brasil (um pequeno centro local no interior de uma região periférica de um país em desenvolvimento). Nesse contexto, há a popularização do acesso a computadores (particularmente ou em Lan Houses) e telefones móveis e, consequentemente, à rede virtual mundial (Internet) e todas as suas decorrentes redes sociais, sítios de relacionamento, notícias e pesquisas. Impõe-se, desta forma, um novo conjunto de variáveis para a análise dos alunos da Educação Básica, visto que são crianças e adolescentes que possuem amplo contato virtual com outros indivíduos (com barreiras/censura/controle cada vez mais permeáveis) e imensa facilidade de acessar informações sobre assuntos diversos (ainda que se questione a validade do que se informa). Como abordou Feitosa, ${ }^{4}$ trata-se de uma geração de "nativos digitais", educada por professores que, no máximo, são "imigrantes digitais". Diferencia-se a forma de lidar com as informações, com os conteúdos trabalhados e, certamente, é necessário que também se modifique/diversifique as formas de comunicação entre esses dois grupos.

Materialmente a sociedade também se modificou nas últimas décadas do século passado. Primeiro, pela ampliação de elementos técnicos disponibilizados para o consumo, depois, em relação ao lugar em que esses "novos" produtos são apresentados: o meio urbano. O mundo tornou-se urbano! O domínio do urbano se dá nas várias esferas da rede. Esteja no campo, numa pequena cidade, ou numa megalópole, o cidadão está sujeito às determinâncias do lugar onde o consumo acontece e as trocas se dão. Santos (1996) já anunciava que "a cidade é o lugar ideal, porque é o lugar onde todo mundo se comunica. Em todo caso se comunica mais do que em outra parte". Esse quadro urbano da sociedade brasileira, na contemporaneidade também cria um fato novo para a prática educativa, pois o espaço determina comportamentos e ações e este cenário externo de formação de territorialidades, de novos esquemas éticos e estéticos não pode, ou não deve, ficar fora dos muros escolares. O professor, que também vive nesse novo contexto, não pode ignorar esse elemento no desenvolvimento das estratégias de comunicação com os seus alunos. 
Um outro elemento fundamental para pensar a prática educativa no contexto brasileiro é a dicotomia que há entre ensino público e privado. Ainda que enfrentem realidades comuns, como as anteriormente citadas, no tocante a infraestrutura, público discente e docente, pode-se afirmar que, no Brasil, têm-se dois tipos bastante distintos de oferta de educação. Essa diferenciação é o espelho da própria sociedade e não deve ser descartada na avaliação de estratégias comunicativas, visto que a variação dos meios técnicos utilizados e do grupo socioeconômico com quem se pretende comunicar impõem códigos diferenciados ao professor.

Pensando especificamente no ensino público, ainda que se entenda a diversidade que cabe dentro dessa categoria, pode-se traçar, em linhas gerais, um cenário maniqueísta da escola que se tem: unidades físicas carentes de infraestrutura adequada à prática educativa, professores mal remunerados e desestimulados, corpo docente com formação acadêmica inadequada ao exercício da profissão, discentes apresentados a um conteúdo depositário que não explica a sua realidade, grades curriculares pouco democráticas, enfim, uma imensa estrutura pulverizada pelo espaço nacional com o trunfo de possuir longo alcance no território, entretanto, oscilando entre a responsabilidade das três esferas de poder público (municipal, estadual e federal) não consegue fugir desse quadro estereotipado acima descrito. As experiências de sucesso são pontuais e fogem à regra e o resultado é mensurado pelos índices de avaliação, seja pelo traço médio, demarcando uma imensa maioria de escolas abaixo do padrão desejado, seja de forma comparativa com outros países.

Relacionado diretamente com o item anterior, na tentativa de se desvincular de um padrão estereotipado do ensino público, destaca-se que, nas duas últimas décadas, duas conquistas foram significantes e apontam para perspectivas animadoras. A primeira diz respeito à tentativa de universalização do acesso ao ensino básico, ${ }^{6}$ mesmo considerando os baixos índices das variáveis qualitativas a isso implicadas (nível cognitivo e qualidade da educação oferecida), a segunda, relacionada ao sistema de cotas que, numa primeira análise, tende a permitir a diversificação do público que alcança o ensino universitário, democratizando-o. Essas duas conquistas, carentes de uma análise mais apurada (não sendo esse o objetivo do texto aqui apresentado), certamente sinalizam para alterações no contexto educacional brasileiro.

Esses quatro elementos, acima sugeridos, indicam um cenário complexo e múltiplo que desemboca, em última escala, no desafio de professores e alunos de conseguirem estabelecer laços comunicativos. Nesse contexto, a diversificação de estratégias parece ser um caminho evidente para alcançar a multiplicidade de experiências que cerca cada indivíduo dentro de uma sala de aula. A ideia de múltiplas inteligên$\operatorname{cias}^{7}$ não é recente, entretanto, na atualidade, ela encontra forte eco frente a realidade de núcleos educativos que extravasam o lugar, expondo a permeabilidade dos muros institucionais a imensa diversidade externa de uma peculiar sociedade local com conexões (mais ou menos intensas) globais. 


\section{Avanços teóricos e aplicação prática de diferentes linguagens nos estudos das Ciências Humanas}

Herança de uma estrutura cartesiana, fragmentada, o conjunto de disciplinas que compõe as grades curriculares dos diversos níveis de formação tem a pretensão de apresentar ferramentas para o entendimento de um dado problema ou dinâmica têmporo espacial. Todavia, a realidade é complexa, plural e alheia às "verdades" disciplinares. Assim, cabe às linguagens ${ }^{8}$ estabelecer interfaces nesse binômio entre os saberes e estruturas disciplinares de um lado e a dinâmica cotidiana do outro.

O texto, mais habitual forma de linguagem utilizada na relação de aprendizagem entre professores e alunos, é apenas uma possibilidade de interação comunicativa que apresenta um ponto de vista, demarcado histórica, cultural e socialmente. Ele é amplamente utilizado nas relações de poder que, cotidianamente, se dão entres os atores envolvidos no estudo e ensino, sendo a própria linguagem, nas suas variadas formas, um código mediador destas relações.

O entendimento de que o texto é apenas uma possibilidade, que existem diversas outras linguagens e que essas formas de comunicação revelam práticas sociais dos atores da educação resulta na apreensão das estratégias comunicativas como instrumentos de se posicionar e manifestar numa sociedade.

Tomando como referência a Geografia e a História, fica evidente como se deu o processo de incorporação dessas linguagens "alternativas" ao longo do tempo:

Na Geografia, como ensinam Corrêa e Rosendahl (2003), a dimensão cultural da sociedade foi privilegiada na análise do espaço desde a origem formal da disciplina, quando a escola francesa abordava a Paisagem Cultural, e, adiante, nos EUA, notadamente na Escola de Berkley, autores como o Carl Sauer, aprofundaram a temática da diversidade cultural através de estudos historicistas acerca das diferentes regiões focadas. Ao longo do século XX, entretanto, a cultura, na Geografia, oscilava segundo as discussões presentes na própria epistemologia da ciência entre a crítica marxista e a dimensão material e quantitativa da Geografia Teorética. Após 1970, decorrente da influência da fenomenologia e dos "humanismos", se fortalece, especialmente na França, a Nova Geografia Cultural, ampliando o sentido de cultura e vendo nesta um fator determinante das relações espaciais. Essa Geografia Cultural se disseminou no Brasil, especialmente na década de 1990, com a fundação do NEPEC (Núcleo de Estudos e Pesquisas sobre Espaço e Cultura) na UERJ, os eventos e periódico (Espaço e Cultura) que regularmente passaram a acontecer.

Essa síntese do processo de incorporação da cultura nas pesquisas em Geografia, historiciza, com todos os riscos das generalizações, a recente multiplicação de estudos e trabalhos que se apropriam de manifestações diversas da sociedade (diferentes formas de expressão e comunicação) como formas possíveis de decifrar dinâmicas territoriais. Assim, também a Geografia aproximou olhares com outros campos disciplinares, como o urbanismo, literatura, história, sociologia e antropologia. 
Na História, a Escola de Annales teve papel essencial para a humanização da disciplina, pois, a partir desta, o estudo acadêmico de História ganhou novos rumos com a crítica a história totalizante do século XIX, segundo Burke (1990), Lucien Febvre e Marc Bloch criaram um solo fértil para que a multidisciplinaridade passasse a ser valorizada nos estudos de História, o que contribuiu para o uso de novos métodos e novas fontes. Essas inovações, do início do século XX, possibilitaram o nascimento da História Cultural que apresenta diversos caminhos para investigação e destaca-se pela valorização das massas anônimas: como o modo de viver, sentir e pensar.

Vale ressaltar o papel do Chartier (1995) no âmbito da História Cultural, especialmente no que se refere às diferentes linguagens expressas nas práticas e representações do fazer social. Qual o papel desse caminho para o trabalho de sala de aula? Essa abordagem foi essencial para que, a partir da década de 90 do século passado, educadores, historiadores e demais especialistas preocupados com a qualidade do ensino das Ciências Humanas buscassem novas estratégias para aproximar o saber escolar do saber histórico acadêmico, no intuito de levar para a disciplina de História dos Ensinos Fundamental e Médio a ênfase na prática social próxima à realidade do aluno, linguagens apropriadas e diversificadas que motivasse o aluno a se sentir parte do processo histórico, bem como agente social com identidade individual e coletiva.

Importante, aqui no Brasil, foi o papel de Pesavento (2005), que se dedicou a analisar as relações entre a História e a Literatura, pois ela destaca o estudo sobre o imaginário que indica formas de ver, sentir e expressar de tempos passados, bem como uma forma de apreensão do mundo: do racional às sensibilidades e emoções.

Por esta via, o saber escolar pode e deve ser apresentado ao aluno na sala de aula de forma mais lúdica, diversa (músicas, filme, imagem, fotografias), pois estas abrem espaço para uma análise do contexto histórico, do passado e também do imaginário de diferentes épocas.

\section{Vínculos entre a teoria e a prática}

Apesar de um certo lapso temporal, as pesquisas e a vanguarda do pensamento da academia acabam repercutindo no direcionamento das práticas pedagógicas, seja pelo viés dos estudos em pedagogia, seja pelo desaguar dos trabalhos vinculados às disciplinas ofertadas nas universidades. Esse "encontro" entre o pensamento acadêmico e a prática educativa acontece de diversas formas: pela própria formação continuada do professor, pela participação em eventos, através do contato com publicações específicas ou por meio de orientações de níveis hierárquicos superiores.

No caso brasileiro, é emblemático como que esse discurso, sobre a necessidade de diversificar a linguagem para atingir os alunos através de diferentes estratégias de comunicação, está presente nas normas que regulam o Ensino Básico. Por exemplo, para Geografia e História os Parâmetros Curriculares Nacionais orientam que

A Geografia em si já é um saber interdisciplinar [...] Decorre daí a necessidade de transcender seus limites conceituais e buscar a interatividade com as outras ciências sem perder sua identidade e espe- 
cificidade. [tratando do ensino de História, afirma-se que] Abre-se aí um campo fértil às relações interdisciplinares, articulando os conhecimentos de História com aqueles referentes à Língua Portuguesa, à Literatura, à Música e todas as Artes, em geral. (BRASIL, 2002, p. 45 e 62$)$.

É claro que do escrito às ações concretas das práticas educativas muito se transforma, pois a prática do professor, conforme escrito anteriormente, passa por uma série de determinâncias, tais quais a motivação, a oferta de infraestrutura e apoio pedagógico da instituição, o desejo e desafio de mudar a ação educativa, a busca pela contínua qualificação na sua profissão, dentre outros. De qualquer forma, em ondas concêntricas, a tendência é que essas práticas alcancem um número crescente de docentes, visto que surgem como alternativa comunicativa diante de uma realidade abrangente e impositiva, na qual, alunos e professores estão, irremediavelmente, envolvidos.

Assim, especialmente nas Ciências Humanas, a diversificação das linguagens a fim de conseguir comunicar-se com o corpo discente está cada vez mais presente nos livros didáticos e, efetivamente, nas salas de aula.

Por conta disso, relaciona-se, a seguir, proposições teóricas e metodológicas ante à prática didática. Nesse momento, mais que estimular o uso de estratégicas comunicativas ou de orientar quando e como fazê-las, objetiva-se, a seguir, discutir quais os desafios que devem ser enfrentados pelo docente que se arvora a utilizar dessas linguagens menos convencionais.

Um primeiro desafio é o da intencionalidade do autor e da obra utilizada. Todo instrumento de comunicação é resultante de um desejo de "dizer" algo. Assim, é decisivo para a interpretação de um trabalho que se conheça a biografia do autor e o que o motivou a produzir/revelar determinada obra. Um bom exemplo está no uso da cartografia histórica como material didático para entender dinâmicas territoriais pretéritas. Os poucos autores de mapas no Brasil Colonial eram, normalmente, engenheiros militares ou artistas cooptados para reproduzir parcialmente o recorte do espaço que interessava aos olhos dos pagantes (Coroa, outros reinos, empreendedores do negócio colonial, etc.). A não observação da intencionalidade do autor no uso desse recurso em sala de aula incorrerá em leituras fragmentadas, parciais e, por vezes, incorretas de antigas dinâmicas espaciais.

$\mathrm{O}$ segundo item a ser observado no uso de diferentes linguagens a fim de comunicar-se com os alunos é a temporalidade que está presente em cada obra. O tempo não é uniforme e sua passagem não é linear. Num mesmo momento histórico podem-se viver diferentes temporalidades, a exemplo do ritmo frenético de um escritório na Avenida Paulista, na metrópole paulistana, e o tempo lento que movimenta o campo na área rural de um município do sertão piauiense; cronologicamente, o momento é o mesmo, entretanto, o tempo não é o mesmo nos dois lugares. A temporalidade está associada ao domínio técnico presente em cada contexto têmporo-espacial. Nesse sentido, cada obra foi produzida numa dada temporalidade e reflete os processos sociais ali, e só ali, vividos. As músicas de Patativa do Assaré, Luiz Gonzaga, ou dos romances de Jorge Amado (Seara Vermelha) e Graciliano Ramos (Vidas Secas), den- 
tre outros que trataram do fluxo migratório do sertanejo em direção às metrópoles do sudeste brasileiro, ao longo das décadas intermediárias do século XX, só são passíveis de legibilidade a partir do entendimento do domínio técnico e do contexto socioespacial daquele tempo/lugar, ou seja, sem entender o sistema de transporte, a rede urbana (e o próprio processo de urbanização) e a estrutura espacial do sertão e do sudeste, o material utilizado perde o sentido. Em outras palavras, não é possível refletir sobre uma dessas obras com o "olhar" e a temporalidade de agora, pois, ainda que os referidos fluxos migratórios continuem a acontecer, o contexto e as formas desses movimentos são outras.

O terceiro desafio que se deve enfrentar, no uso de diferentes estratégias comunicativas, é estar atento à multiplicidade de formas de apreensão do Espaço Geográfico. O espaço é sempre muito mais complexo do que os nossos sentidos podem apreender dele. Uma obra exprime elementos do espaço, mas nunca toda a sua dinâmica. Cabe, todavia, ao olhar do professor que vai utilizar determinada obra, a atenção ao que está explícito em cada comunicação e aos incontáveis elementos "invisíveis" dentro de uma obra, muitos deles decorrentes da intencionalidade do autor, outros não vistos pelo próprio autor. Imagine uma imagem, na década de 1960, de Pierre Verger que retratou a diversidade dos negros da cidade da Bahia. De início, é perceptível um tema central, a ideia capital que motivou o trabalho. Com sucessivos olhares, penetrando na obra, será possível ver uma intricada malha de informações periféricas que se entrecruzam na imagem e que também se comunicam com o observador. No caso específico das imagens, como já escreveu Santos (1997, p. 83), "a paisagem é o conjunto de formas que, num dado momento, exprimem as heranças que representam as sucessivas relações localizadas entre homem e natureza. O espaço são essas formas mais a vida que as anima". Ou seja, na paisagem as imagens dão diversas informações, mas o conteúdo completo só é dado pela dinâmica do espaço: objetos e ações.

Por fim, relaciona-se como último cuidado a ser tomado a observação da polissemia do instrumento utilizado. Textos, imagens, sons, danças são formas de comunicação que trazem consigo imensa diversidade interpretativa. Na preparação de uma obra para uso em sala de aula, o professor deve estar atento às possibilidades que guardam as obras trabalhadas, mas, principalmente, respeitar e valorizar o olhar do outro sobre o material utilizado. Cada indivíduo lerá a obra a partir do seu ferramental, da sua experiência acumulada e, possivelmente, verá coisas diferentes. Essa diversidade de olhares, antes de se constituir num problema ao uso dessas linguagens, é um dos seus fatores mais atrativos.

\section{Considerações finais}

Diante da dificuldade de colocar termos finais nesse texto que versa sobre uma temática tão frutífera e inconclusa, tenta-se, a seguir, em alternativa a uma conclusão peremptória do artigo, esclarecer linhas de raciocínio, sugestões à continuidade da discussão e, especialmente, induções à práticas didáticas criativas.

Um pressuposto fundamental, presente na argumentação desse artigo, é que o aprendizado é pessoal e subjetivo derivando, por conseguinte, de estratégias dife- 
renciadas de acesso ao saber e do próprio significado do dito "saber". Desmistifica-se, assim, a ideia de uma ferramenta adequada para acessar o conhecimento. Mais que isso, há, invariavelmente, uma diversidade de estratégias possíveis para apreender um dado objeto e o ferramental a ser utilizado será, sempre, decorrente da combinação absolutamente heterogênea entre a instituição de ensino (estrutura física, perfil ideológico, projeto pedagógico, etc.), a formação e motivação do professor e o aluno (contexto socioeconômico e individualidade de cada discente).

É nesse contexto impreciso que se impõe estabelecer o diálogo entre a teoria e a prática. Ou seja, aproximar o discurso acadêmico e mesmo a leitura de mundo dos docentes do exercício empírico do cotidiano escolar. Assim, a diversidade de ferramentas comunicativas parece um caminho lógico para alcançar uma comunicação mais abrangente entre professores e alunos.

Essas considerações nada mais são que especulações teóricas. Recorrendo a Martins (1995), ratifica-se que a "didática prática" não é um espelho da "didática teórica”, sendo aquela muito mais heterogênea e dinâmica que esta, visto que deriva de opções metodológicas (nem sempre embasadas em teorias) e práticas didáticas de cada educador, bem como das possibilidades relacionais entre os agentes envolvidos na construção da educação formal.

Mormente a sua usual participação secundária na construção do currículo e, mesmo, no planejamento das atividades didáticas, o discente possui papel decisivo no ato comunicativo, visto que ele é o agente sobre o qual incidem os objetivos da ação educacional. Nesse sentido, é imperativo estimular o papel ativo do aluno como um dos elementos da troca que deve se constituir os encontros educativos. O respeito a esse papel do discente passa, necessariamente, pela diversificação nas estratégias de se comunicar. Esse é o ponto nodal abordado neste escrito.

Entendendo os limites do breve texto de um artigo e também que diversos outros autores já se debruçaram sobre a temática, acredita-se que esta é mais uma contribuição que tenta associar o debate teórico à didática prática, ao exercício cotidiano do docente na busca incessante de se comunicar com os discentes.

Procurou-se, assim, além de estabelecer diálogo com outros autores, contextualizar a nossa contemporaneidade e apresentar possibilidades de uso de diferentes estratégias comunicativas, notadamente, aquelas relacionadas ao ensino das Ciências Humanas.

Ratifica-se que as sugestões do texto não são definitivas e excludentes. Há, certamente, uma variedade enorme de formas de se comunicar para além das apresentadas, dentre as quais se pode enumerar: a dança, as manifestações folclóricas, os grafites, a documentação histórica, a cartografia histórica, os poemas e poesias, os desenhos, as "tiras", as charges, as notícias de jornais, dentre outros.

Em suma, acredita-se que no "jogo" de sombras e luzes das pinturas de Caravaggio, nos sons dos tambores do Olodum, na beleza crua e nua das imagens de Pierre Verger, no deslumbrante desenho arquitetônico das igrejas de Ouro Preto, nas 
letras da poesia rude e, ao mesmo tempo, refinada de Patativa do Assaré, nos contos de Levy Tolstoy e em tantas outras formas de arte que se comunicam e emocionam, há, certamente, uma imensa possibilidade de uso didático para humanizar o saber presente nos planos de disciplinas. Estabelecer essa ponte é um desafio estimulante que se apresenta aos docentes, um verdadeiro convite à criatividade, emoção e conhecimento.

\section{Referências}

ANDRADE, A. B. Novas variáveis para o trato do território na contemporaneidade. Finisterra. Revista Portuguesa de Geografia. v. XLV, n. 89. Lisboa/Portugal: Centro de Estudos Geográficos, 2010. p. 157-170.

ARANHA, M. L. de A.; MARTINS, M. H. P. Filosofando. Introdução à Filosofia. Pensamento e Linguagem. 3a edição revista. São Paulo. Editora Moderna, p. 34, 2007.

BRASIL. Ministério de Educação e do Desporto. Parâmetros Curriculares Nacionais. Brasília/ DF: Secretaria de Educação, 2002.

BURKE, P. A Escola dos Annales (1929-1989): a Revlução Francesa da Historiografia. Tradução Nilo Odalia. São Paulo, Unesp, 1997.

CAMPBELL, L.; CAMPBELL, B.; DICKINSON, D. Ensino e Aprendizagem por meio das Inteligências Múltiplas. 2.ed. Trad. LOPES, M. F. Porto Alegre: Artes Médicas Sul, 2000

CHARTIER, R. História Cultural: entre práticas e representações. Rio de Janeiro, Betrand, 1990.

CORRÊA, R. L.; ROSENDAHL, Z. (Org.). Introdução à geografia cultural. Rio de Janeiro: Bertrand Brasil, 2003.

CURY, C. R. J. A Educação Básica no Brasil. In: Revista Educação e Sociedade. v. 23, n.80. Campinas: Unicamp, set/2002, p. 168-200. Disponível em <http.//www.cedes.unicamp.br>. Acesso em: 22 ago. 2012.

FREIRE, P. Pedagogia da autonomia: saberes necessários à prática educativa. 25a ed. São Paulo: Paz e Terra, 1996. (Coleção Leitura)

KOSHIBA, L. História do Brasil no contexto da história ocidental. São Paulo, Ed. Atual, 2002.

MARTINS, P. L. O. Didática Teórica/Didática Prática. Para além do confronto. $4^{a}$ ed. São Paulo: Edições Loyola, 1995.

PESAVENTO, S. J. História \& história cultural. 2a Edição. Belo Horizonte: Autêntica, 2005.

SANTOS, M. Um encontro: Gilberto Gil e o Professor Milton Santos. Web Design Gege Produções Artísticas. Disponível em: <http://www.gilbertogil.com.br>. Acesso em: 30 nov. 2010. Realizada em: 1996.

SANTOS, M. A natureza do espaço. Técnica e Tempo. Razão e Emoção. $2^{a}$ ed. São Paulo: Hucitec, 1997. 


\section{Notas}

${ }^{1}$ Não obstante o entendimento de que a terminologia Ciências Humanas é muito mais abrangente, optouse, neste artigo, por tratar especificamente com as disciplinas de Geografia e História, por conta do vinculo profissional e formação acadêmica dos autores com estas áreas do saber.

${ }^{2}$ Utiliza-se "dinâmica têmporo-espacial”, sustentado no pensamento miltoniano (SANTOS, 1997), que ensina que todo evento é uma realização específica e peculiar num dado tempo e espaço. Considerando então que espaços comuns podem viver diferentes temporalidades e que num mesmo tempo cronológico os espaços se diferenciam a partir dos diferentes conteúdos técnicos, acredita-se na importância de, ao pensar as estratégias comunicativas a serem abordadas, ter clareza sobre a dinâmica territorial e a temporalidade técnica que se vive na realidade concreta da cidade/escola/sala de aula.

${ }^{3}$ Segundo Santos (1997, p.225) "Pontos no espaço que, separados uns dos outros, asseguram o funcionamento global da sociedade e da economia”.

${ }^{4}$ Palestra realizada no V Simpósio de Educação do Colégio Militar de Salvador, em 21 de outubro de 2010. Alessandra Martins Gomes Feitosa, então Major do Quadro de Magistério do Exército Brasileiro e mestranda em Letras pela UERJ, era coordenadora do Projeto Letramento da Diretoria de Ensino Preparatório e Assistencial e desenvolvia pesquisa sobre níveis de letramento na escrita.

${ }^{5}$ Entende-se por "nativos digitais" a geração pós-1990, educada em níveis básicos com forte inserção na manipulação de equipamentos de inovação tecnológica, mormente as tecnologias de comunicação e informação desenvolvidas em escala exponencial com a revolução técnico-científica informacional engendrada na segunda metade do século XX; ao passo que os "imigrantes digitais" são aqueles de gerações anteriores que se adequaram ao uso dessas novas tecnologias à medida da necessidade e, certamente, num momento posterior à sua formação escolar básica.

${ }^{6}$ Sobre essa temática, convém recorrer à interessante análise de Cury (2002) que relativiza a apregoada universalização do acesso ao passo que, sustentado em dados e textos da lei, aponta para as perspectivas de avanço recente - pós Constituição de 1988 - na educação formal no Brasil, notadamente no âmbito do Ensino Básico.

${ }^{7}$ Em seu livro de 1983, Estruturas da Mente, Gardner apresentou sua Teoria das Inteligências Múltiplas, que reforça sua perspectiva intercultural da cognição humana. As inteligências são linguagens que todas as pessoas falam e são, em parte, influenciadas pela cultura em que a pessoa nasceu. São ferramentas para a aprendizagem, resolução de problemas e criatividade que todos os seres humanos podem usar. (CAMPBELL; CAMPBELL; DICKSON, 2000, p.22)

${ }^{8}$ Entende-se por "linguagens", conforme Aranha e Martins (2007), as diversas formas comunicativas de alcance ao interlocutor, perpassando por estratégias visuais, sensitivas, orais, escritas, dentre outras. Assim, diversificar linguagens, no contexto de uma sala de aula, significa utilizar de diferentes formas de abordagem dos objetos, contemplando diferentes perspectivas de alcance do conteúdo trabalhado. A linguagem é um produto sofisticado que só a razão humana pode criar. Considerando o seu caráter simbólico, ela se adequa à cultura dentro da qual se desenvolve, estruturando pontes entre o pensamento, no mundo das ideias, e a comunicação com o interlocutor que a recepciona de forma polissêmica, dando sentidos próprios ao que foi comunicado. 
* Professor Doutor do Colégio Militar de Brasília. Brasília, Distrito Federal, Brasil.

** Professora Mestre do Colégio Militar de Salvador, Salvador, Bahia, Brasil.

*** Professora Mestre do Colégio Militar de Salvador, Salvador, Bahia, Brasil.

\section{Correspondência}

Adriano Bittencourt Andrade - Colégio Militar de Brasília. SGAN 902/904, Asa Norte. CEP: 70790-020, Brasília, Distrito Federal, Brasil.

E-mail: abittandrade@hotmail.com-ncjmhist@oi.com.br - lilavarino@gmail.com

Recebido em 28 de julho de 2014

Aprovado em 31 de outubro de 2014 
